\title{
A tomography image of the Aegean region (Greece) derived from inversion of macroseismic intensity data
}

\author{
George N. Stavrakakis, George Drakatos, George Karantonis and Dimitris Papanastassiou \\ National Observatory of Athens, Institute of Geodynamics, Athens, Greece
}

\begin{abstract}
The three-dimensional attenuation structure beneath the Aegean sea and the surrounding regions was determined by inversion of seismic intensity data. A large number of seismic intensity data have been accumulated in a uniform scale in the Aegean region, where the seismic activity is much higher than that of the other Mediterranean regions. Nearly 11000 seismic intensity data from 47 earthquakes that have occurred in these regions were used to determine the seismic attenuation structure. The resulting structure reveals a remarkable contrast of attenuation. In the top layer (depth $0-20 \mathrm{~km}$ ), low $Q$ is dominant in the central Aegean sea, while high $Q$ is dominant in the surrounding land areas, except for Southwestern Turkey. The low- $Q$ regions correspond to areas of Neogene-Quaternary grabens where the high seismicity of shallow earthquakes appears. In the lower layer $(20-40 \mathrm{~km})$ low- $Q$ areas are located in the southeastern part of the Hellenic arc. Some low- $Q$ spots corresponding to the distribution of volcanoes exist along the volcanic arc. The low- $Q$ spots might correspond to diapirs causing subduction volcanism.
\end{abstract}

Key words tomography - $3 D$ - structure Greece

\section{Introduction}

The region of the Aegean sea and the surrounding areas in the Eastern Mediterranean lie on a boundary zone between the Eurasian and the African plates (e.g. McKenzie, 1970). The region is a zone of widespread deformation within which complex relationships exist between extensional, compressional, and strikeslip deformations (e.g. McKenzie, 1978; Dewey and Sengor, 1979; Le Pichon and Angelier, 1979). As expected in an area of extensive deformation, this reveals high seismic ac-

Mailing address: Dr. George N. Stavrakakis, National Observatory of Athens, Institute of Geodynamics, P.O. Box 20048, 118-10 Athens, Greece; e-mail: g.stavr@ egelados.gein.noa.gr tivity, the highest in Europe. Most of the seismicity is associated with the Hellenic arc, zones of Western Anatolia, and Greece (Papazachos, 1973).

The Hellenic arc shows remarkable features of island arcs such as the existence of intermediate depth earthquakes, and volcanic activity. The African plate is moving northeastward relative to the Aegean plate (McKenzie, 1970; Papazachos, 1973), and is subducting under the Western Hellenic arc with a dip angle of $30^{\circ}$ $40^{\circ}$ (e.g. Papazachos and Comninakis, 1971; Papazachos, 1973). These features are summarized in fig. 1.

Other geophysical observations also show that the Aegean region is in an anomalous tectonic setting. Heat flow data indicate high heat flow with a mean value of $2.1 \mathrm{HFU}$ in the Northern and Central Aegean sea (Jongsma, 1974). A compilation of gravity data shows a large positive gravity anomaly in the Aegean sea, while negative anomalies are observed in 


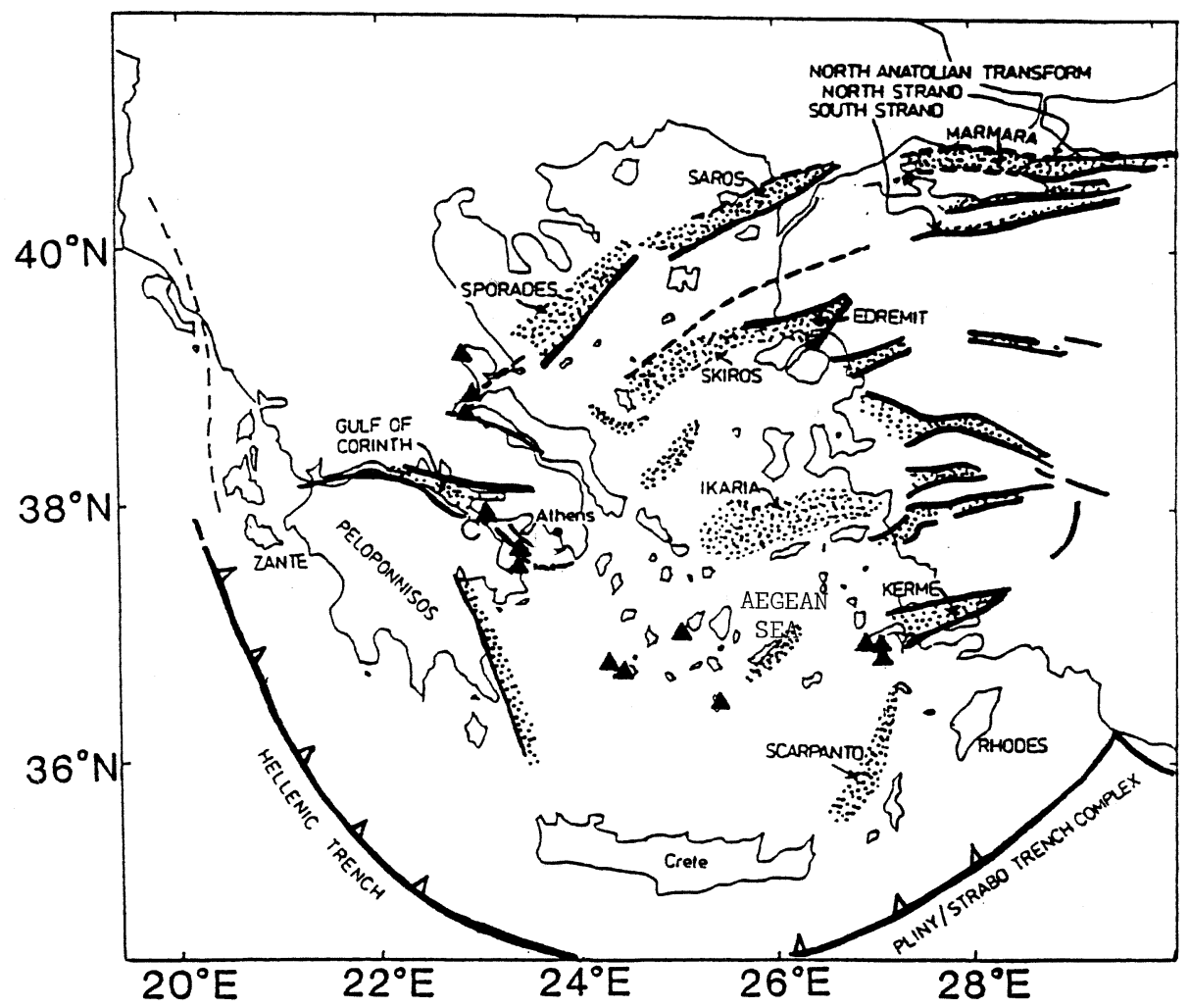

Fig. 1. A simplified summary of Aegean tectonics, following Dewey and Sengor (1979). The heavy lines with and without open triangles indicate the subduction zone and faults, respectively. The broken lines show poorly defined faults. The stippled areas show Neogene-Quaternary grabens. Volcanoes are shown by the solid triangles (Ninkovitch and Hays, 1972; Fytikas et al., 1976).

Turkey and in the Greek mainland (Makris, 1976).

Crustal structure in the Aegean region was studied by Makris (1978). He found that the crustal thickness under Peloponnesos is $46 \mathrm{~km}$ but under the Central Aegean sea the crustal thickness decreases to $26 \mathrm{~km}$. He also found a low $P_{n}$ velocity of $7.7 \mathrm{~km} \mathrm{~s}^{-1}$ in the region. Papazachos and Comninakis (1978) proposed a mean crustal thickness of about $22 \mathrm{~km}$ in the Eastern Mediterranean, based on seismic refraction, seismic reflection, surface wave dispersion, and gravity data.

Lateral variation of the velocity structures in the Aegean region has also been investigated in terms of its tectonics. Gregersen (1977) investigated the shape of the dipping plate from travel time residuals. Jacoby et al. (1978) found a high-velocity slab and a low-velocity upper mantle above the dipping slab from the analysis of travel time residuals. Delibasis (1982) discussed seismic wave attenuation in the upper mantle due to the inhomogeneous velocity structure beneath the Aegean region. Recently, Spakman (1985) estimated the threedimensional velocity structure by tomographic inversion of travel times.

In this paper, we attempt to estimate a three-dimensional seismic attenuation structure beneath the Aegean sea and the surrounding 
regions. The attenuation structure is estimated by an inversion technique of seismic intensity data. The tectonic implication of the results will be discussed.

The first systematic study on the attenuation of intensities with distance for shallow earthquakes in the area of Greece was done by Drakopoulos (1978). He concluded, by inspection of some isoseismal lines, that the seismic energy of intermediate shocks is strongly attenuated in the inner part of the Aegean arc. Papazachos and Comninakis (1971) noted that the feature of the isoseismals of all intermediate shocks shows an elongation along the Hellenic arc. They explained the phenomena by the existence of a highly absorptive region in the upper mantle beneath the inner part of the arc. Thus, our study is a natural extension of their studies, since we estimate the inhomogeneity of absorption quantitatively.

\section{Method}

Hashida and Shimazaki (1984) developed a technique for estimating three-dimensional $Q$ structure by a damped least-squares inversion of macroseismic data. Details of the method are given by them, so we only briefly outline the basic concepts of the inversion.

The seismic intensity data which measure the degree of ground shaking contain information on the «size» of earthquake source and attenuation along the path from the focus to the stations. By using the formula of Gutenberg and Richter (1942, 1956), the intensity $I$ given in the Modified Mercalli (MM) scale is converted to the acceleration $\alpha$ (Gal) of $S$-wave, as follows:

$$
\alpha=10^{I / 3-0.5}
$$

By taking spatially heterogeneous attenuation of intensity into account, the acceleration $\alpha$ at a station can be formulated as follows:

$$
\alpha=S G g \exp \left(-\sum_{k} D_{k} \cdot T_{k}\right),
$$

where $S$ is the acceleration at the seismic source; $G$ is the geometrical spreading factor; $g$ is the amplifying effect at the Earth's surface; $D_{k}$ is the attenuation coefficient $\left(\mathrm{s}^{-1}\right)$ in the $k$-th block region and $T_{k}$ is the travel time (s) in the $k$-th block region.

$S$ is assumed to be radiated at the seismic source isotropically. Summation $\sum_{k}$ is made over block regions where the seismic ray penetrates.

The attenuation coefficient $D_{s}$ for $S$-waves is related to the quality factor $Q_{s}$ as follows:

$$
D_{s}=\pi f / Q_{s}
$$

where $f$ is a representative frequency related to seismic intensity. Generally the representative frequency is considered to be around $1 \mathrm{~Hz}$, varying from event to event and/or station to station. Because of limited information on the frequency from intensity data, we use attenuation coefficient $D$ instead of $Q$ value in this study. Weak attenuation corresponds to high $Q$, and vice versa.

First we assume a horizontally layered attenuation structure as the starting model, in which the attenuation coefficient $D_{0 k}$ is given. We can then calculate the initial acceleration $S_{0}$ at the source from the observed acceleration $\alpha^{\text {obs }}$ as follows:

$S_{0}=\frac{1}{N_{s}} \sum_{i} \alpha_{i}^{\mathrm{obs}} / G_{i} g_{i} \cdot \exp \left(-\sum_{k} D_{0 k} \cdot T_{k, i}\right)$

where $N_{s}$ means number of stations and summation $\sum_{i}$ is made over stations reporting intensities. Actually the effect of ground amplification $g_{i}$ is fixed to be 2.0 for all stations by only taking the free-surface effect into account. Now we can get a calculated acceleration at the $i$-th station, $\alpha_{i}^{\text {cal }}$ from eq. (2.2) based on the initial structure $D_{0 k}$ and the initial acceleration at source $S_{0}$.

By taking the difference between the natural logarithms of the observed and calculated accelerations, which is denoted by $O-C$ hereafter, we get the following observational equation:

$\ln \alpha^{\mathrm{obs}}-\ln \alpha^{\mathrm{cal}}=\delta S-\sum_{k} \delta D_{k} \cdot T_{k}+e$ 
where $\delta D_{k}=D_{k}-D_{0 k}$ and $\delta S=\ln \left(S / S_{0}\right)$.

We assume the same geometrical spreading factor $G$ for the observed and calculated accelerations, which implies that the variation in $S$-wave velocity is much smaller than the variation in attenuation. Thus, the error $e$ includes not only observational error mainly due to conversion of intensity to acceleration by using eq. (2.1) but also parametric error due to simplified formulation of the problem.

Perturbations $\delta S$ for each event and $\delta D_{k}$ for the $k$-th block are determined by solving a set of observational equations given by eq. (2.5) for many pairs of event and station. We can estimate perturbations $\delta S$ and $\delta D$ together by the damped least-squares inversion which simulta- neously minimizes the squared sum of $e$ and that of perturbations. More detailed description on the inversion is given in Hashida and Shimazaki (1984) and Aki and Lee (1976).

\section{Data and inversion procedure}

Data consist of seismic intensities corresponding to 47 earthquakes which occurred in Greece and surrounding areas, as shown in fig. 2. Table I summarizes their parameters. The intensity data are taken from the monthly bulletins of the Institute of Geodynamics of the National Observatory of Athens (NOA). The intensities for the earthquakes investigated are

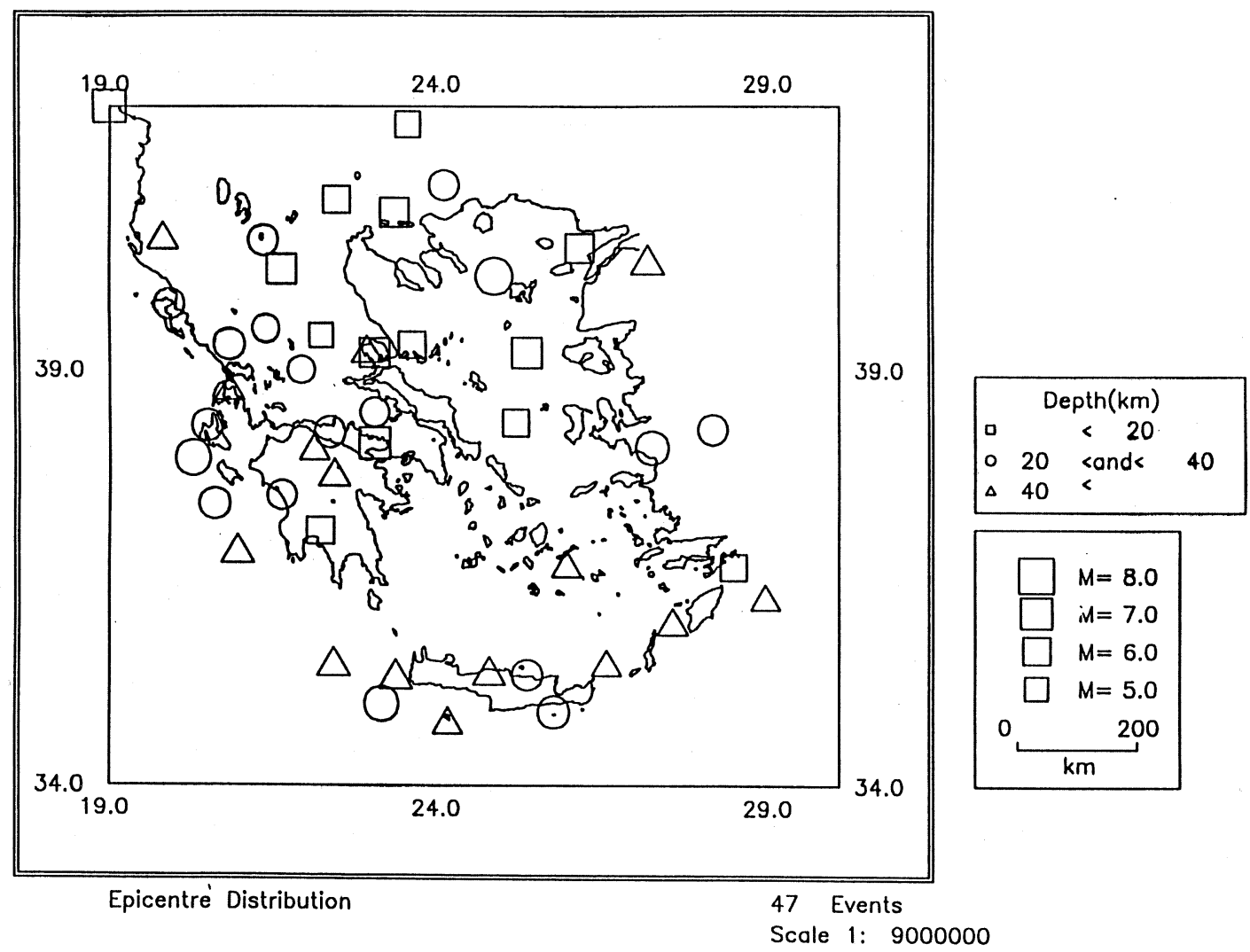

Fig. 2. The earthquakes used in this study are shown. 
Table I. Earthquake parameters.

\begin{tabular}{|c|c|c|c|c|c|c|c|c|}
\hline \multicolumn{2}{|c|}{ Date } & \multicolumn{3}{|c|}{$\begin{array}{l}\text { Origin } \\
\text { time }\end{array}$} & \multirow{2}{*}{$\begin{array}{c}\begin{array}{c}\text { Lat. } \\
(\mathrm{N})\end{array} \\
41.80\end{array}$} & \multirow{2}{*}{$\begin{array}{c}\begin{array}{c}\text { Long. } \\
\text { (E) }\end{array} \\
23.50\end{array}$} & \multirow{2}{*}{$\begin{array}{c}\begin{array}{c}\text { Depth } \\
(\mathrm{km})\end{array} \\
10\end{array}$} & \multirow{2}{*}{$\begin{array}{l}M_{s} \\
5.5\end{array}$} \\
\hline 1972 & May. 8 & 09 & 20 & 51.0 & & & & \\
\hline 1972 & Sep. 13 & 04 & 13 & 23.0 & 37.80 & 22.40 & 40 & 5.9 \\
\hline 1974 & Jul. $\quad 9$ & 02 & 32 & 9.0 & 36.30 & 28.90 & 69 & 5.5 \\
\hline 1974 & Nov. 14 & 15 & 29 & 44.0 & 38.50 & 23.00 & 20 & 5.3 \\
\hline 1975 & Mar. 27 & 05 & 15 & 6.0 & 40.40 & 26.10 & 15 & 6.2 \\
\hline 1975 & Apr. 4 & 05 & 16 & 18.0 & 38.10 & 22.10 & 56 & 5.6 \\
\hline 1976 & Feb. 22 & 12 & 02 & 51.0 & 39.40 & 22.20 & 15 & 5.1 \\
\hline 1977 & Feb. 24 & 20 & 47 & 14.0 & 38.30 & 28.10 & 25 & 5.5 \\
\hline 1977 & Sep. 11 & 23 & 19 & 22.0 & 35.00 & 23.10 & 30 & 6.4 \\
\hline 1977 & Nov. 28 & 02 & 59 & 11.0 & 36.00 & 27.50 & 79 & 5.7 \\
\hline 1978 & Jan. 29 & 10 & 23 & 42.0 & 34.90 & 25.70 & 35 & 5.9 \\
\hline 1978 & Apr. 27 & 08 & 33 & 27.0 & 39.00 & 21.90 & 39 & 5.0 \\
\hline 1978 & Jun. 20 & 20 & 03 & 21.0 & 40.80 & 23.30 & 15 & 6.5 \\
\hline 1979 & Feb. 16 & 04 & 28 & 18.0 & 36.70 & 25.90 & 40 & 5.5 \\
\hline 1979 & Apr. 15 & 06 & 19 & 42.0 & 42.00 & 19.00 & 15 & 7.3 \\
\hline 1979 & Jun. 15 & 11 & 34 & 13.0 & 34.80 & 24.10 & 40 & 5.6 \\
\hline 1979 & Jul. 23 & 11 & 41 & 51.0 & 35.50 & 26.50 & 50 & 5.6 \\
\hline 1980 & Jul. $\quad 9$ & 02 & 11 & 54.0 & 39.20 & 23.00 & 10 & 6.5 \\
\hline 1981 & Feb. 24 & 20 & 53 & 36.0 & 38.14 & 23.00 & 15 & 6.8 \\
\hline 1981 & Mar. 10 & 15 & 16 & 18.0 & 39.30 & 20.80 & 35 & 5.8 \\
\hline 1981 & Dec. 19 & 14 & 10 & 49.0 & 39.20 & 25.30 & 17 & 6.8 \\
\hline 1982 & Jun. 22 & 03 & 04 & 28.3 & 36.88 & 20.93 & 40 & 6.3 \\
\hline 1982 & Nov. 16 & 23 & 41 & 27.6 & 40.54 & 19.80 & 41 & 5.8 \\
\hline 1983 & Jan. 17 & 12 & 41 & 30.9 & 37.97 & 20.25 & 20 & 6.7 \\
\hline 1983 & Mar. 16 & 21 & 19 & 39.1 & 38.79 & 20.81 & 43 & 5.5 \\
\hline 1983 & Mar. 19 & 21 & 41 & 49.2 & 35.35 & 25.30 & 28 & 5.7 \\
\hline 1983 & Jul. $\quad 5$ & 12 & 01 & 30.7 & 40.27 & 27.13 & 42 & 6.4 \\
\hline 1983 & Aug. 6 & 15 & 43 & 53.3 & 40.08 & 24.81 & 22 & 7.1 \\
\hline 1984 & Jun. 21 & 10 & 43 & 46.2 & 35.36 & 23.31 & 46 & 6.4 \\
\hline 1984 & Oct. 25 & 14 & 38 & 25.5 & 40.49 & 21.32 & 20 & 5.6 \\
\hline 1985 & Apr. 30 & 18 & 14 & 12.8 & 39.24 & 22.89 & 79 & 5.8 \\
\hline 1985 & Nov. 9 & 23 & 30 & 45.6 & 41.11 & 24.05 & 23 & 5.6 \\
\hline 1986 & Mar. 25 & 01 & 41 & 36.8 & 38.38 & 25.13 & 16 & 5.7 \\
\hline 1986 & Sep. 13 & 17 & 24 & 33.8 & 37.10 & 22.19 & 13 & 6.0 \\
\hline 1986 & Dec. 17 & 21 & 18 & 33.1 & 39.76 & 19.90 & 26 & 5.6 \\
\hline 1987 & May. 29 & 18 & 40 & 33.2 & 37.53 & 21.60 & 29 & 5.5 \\
\hline 1988 & May. 18 & 05 & 17 & 42.7 & 38.35 & 20.47 & 20 & 5.8 \\
\hline 1989 & Mar. 19 & 05 & 37 & .2 & 39.29 & 23.57 & 13 & 5.8 \\
\hline 1989 & Sep. 19 & 07 & 57 & 7.6 & 39.48 & 21.36 & 36 & 5.0 \\
\hline 1990 & Dec. 21 & 06 & 57 & 43.3 & 40.95 & 22.43 & 15 & 5.9 \\
\hline 1992 & Nov. 6 & 19 & 08 & 8.4 & 38.09 & 27.19 & 39 & 6.2 \\
\hline 1992 & Nov. 18 & 21 & 10 & 43.1 & 38.27 & 22.33 & 23 & 5.7 \\
\hline 1992 & Nov. 21 & 05 & 07 & 19.0 & 35.51 & 22.38 & 78 & 6.3 \\
\hline 1993 & Aug. 26 & 10 & 03 & 53.7 & 36.66 & 28.42 & 17 & 5.7 \\
\hline 1994 & Apr. 16 & 23 & 09 & 36.4 & 37.43 & 20.58 & 30 & 5.8 \\
\hline 1994 & May. 23 & 06 & 46 & 16.3 & 35.40 & 24.73 & 79 & 6.1 \\
\hline 1995 & May. 13 & 08 & 47 & 00.0 & 40.16 & 21.60 & 16 & 6.6 \\
\hline
\end{tabular}




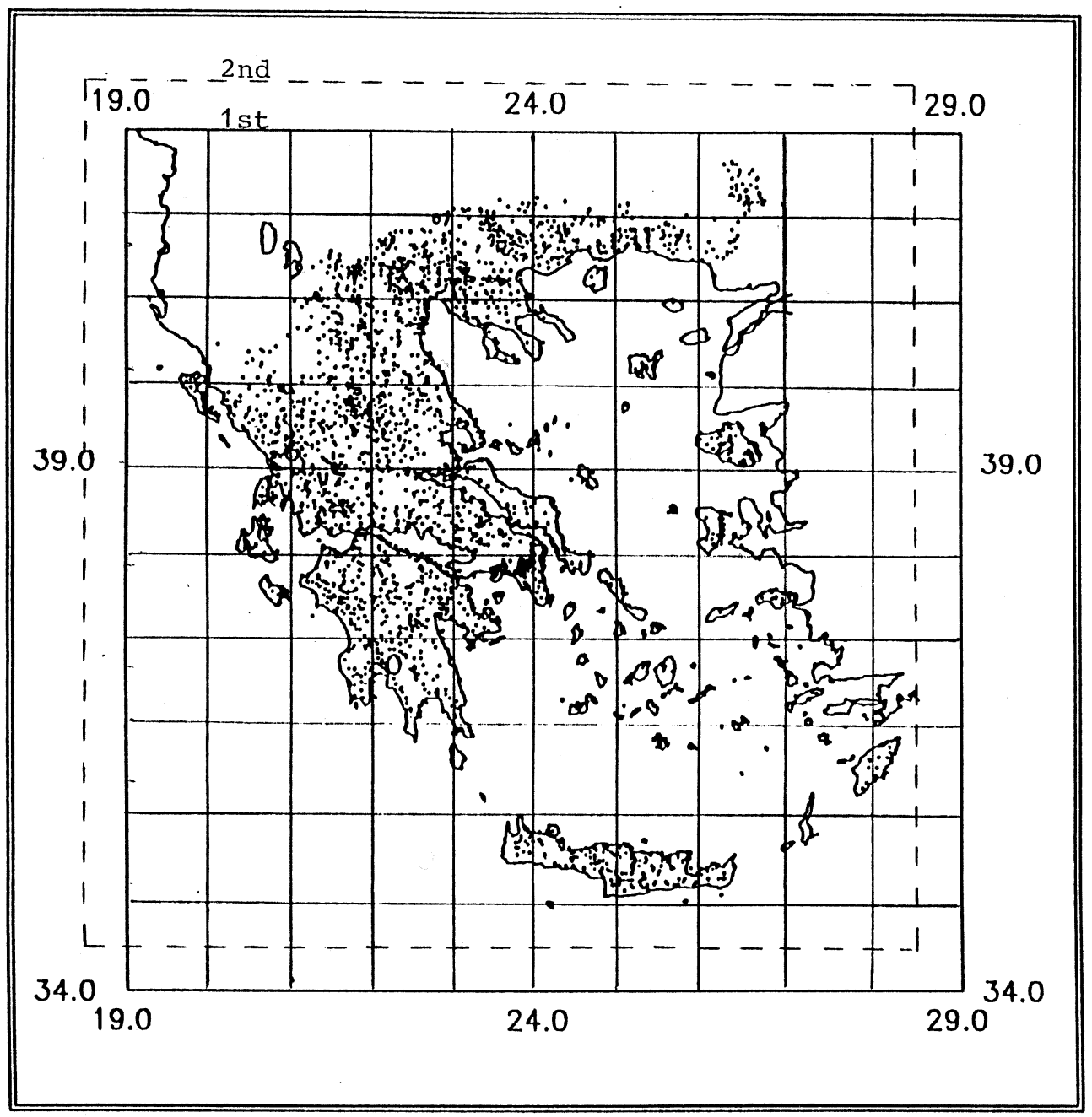

Fig. 3. The intensity data used in this study are shown. Small points are the location of intensity data taken from the monthly bulletins of Institute of Geodynamics of NOA. The two block configurations used in this study are also shown.

given in MM (Modified Mercalli) scale. In this way, 10482 intensity data were obtained and are plotted in fig. 3 .

The crust was divided into two layers; the thickness of each layer is $20 \mathrm{~km}$. Each layer was divided into $10 \times 10$ blocks. The block sizes are $90 \mathrm{~km}$ and $80 \mathrm{~km}$ in the E-W and N-S directions, respectively. The block configuration is shown in fig. 3. The initial values of the attenuation coefficient are $7.85 \times 10^{-3}$ and 3.14 $\times 10^{-2} S^{-1}$ for the upper and the lower layers, respectively.

By assuming that the frequency of $S$ waves related to the seismic intensity is $1 \mathrm{~Hz}$, initial values are converted to $Q=400$ and $Q=100$, respectively, for the upper and lower layers. These $Q$ values are almost equal to those of the standard Earth model SL8 determined by An- 
derson and Hart (1978), who estimated a global $Q$ structure using longer period seismic data. As we assume that the variations of the $S$-wave velocity $V_{s}$ is much smaller than that of the $S$-wave attenuation $D\left(\delta V_{s} / V_{s} \ll \delta D / D\right)$ the $S$-wave velocities are fixed to be $3.8 \mathrm{~km} \mathrm{~s}^{-1}$ and $4.3 \mathrm{~km} \mathrm{~s}^{-1}$ for the upper and lower layers, respectively.

Initial values for source acceleration were calculated from the observed macroseismic data and the initial attenuation model. Then, the data were inverted to obtain the 3D attenuation structure. Although a flat-layer was used instead of a spherical-layer structure, the corrections are small and are ignored. This is because the horizontal extent of each block is much smaller than the radius of the Earth and the error induced by ignoring the correction is much smaller than the observation error, which is mainly due to the conversion of intensity into acceleration.

Then, the ray paths from events to observation points and the corresponding travel times in the blocks were calculated. Figure $4 a, b$ shows the ray paths for each layer. Despite the small number of events used, ray coverage is

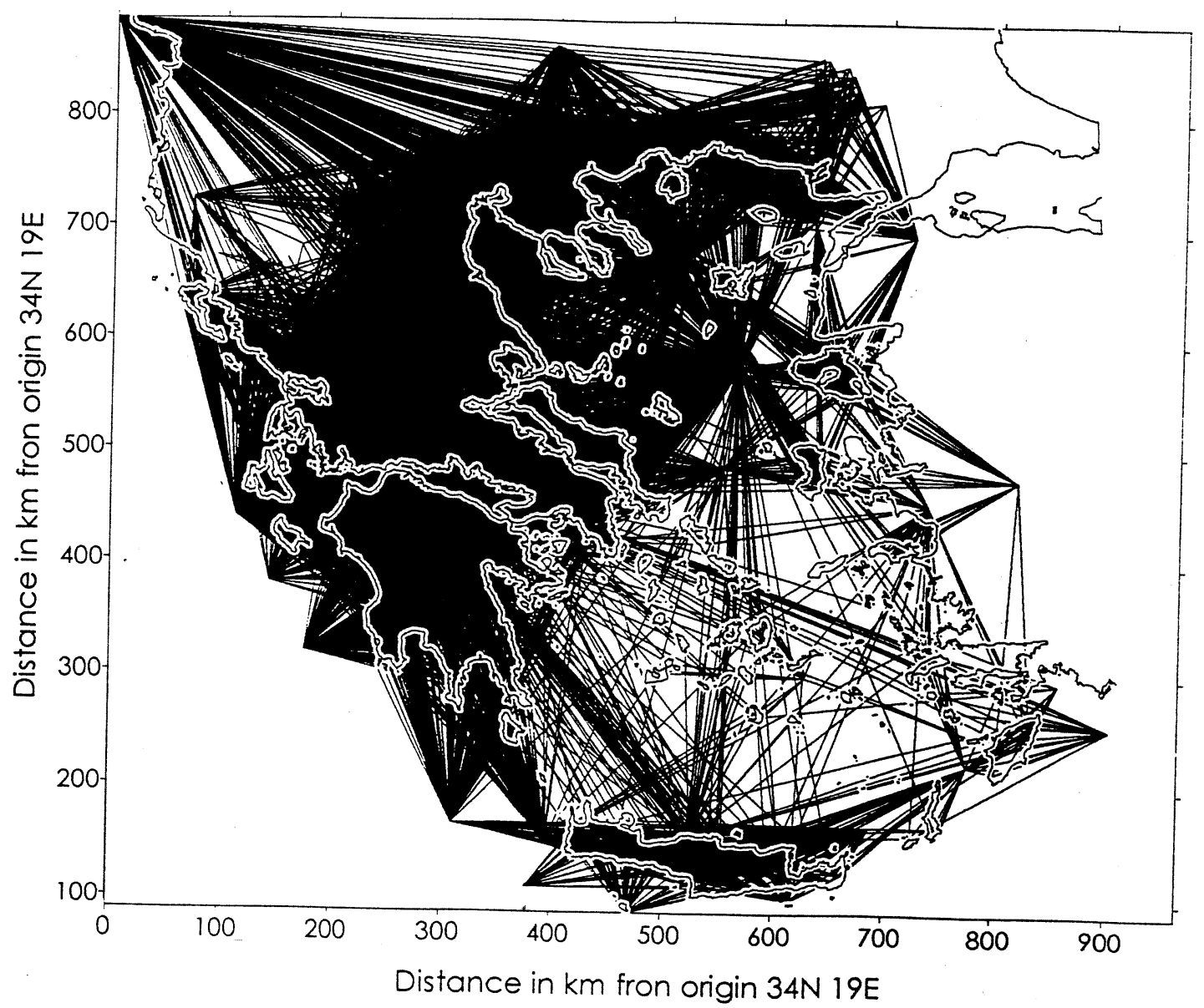

Fig. 4a. The ray path coverage of the region is shown for the upper layer. 


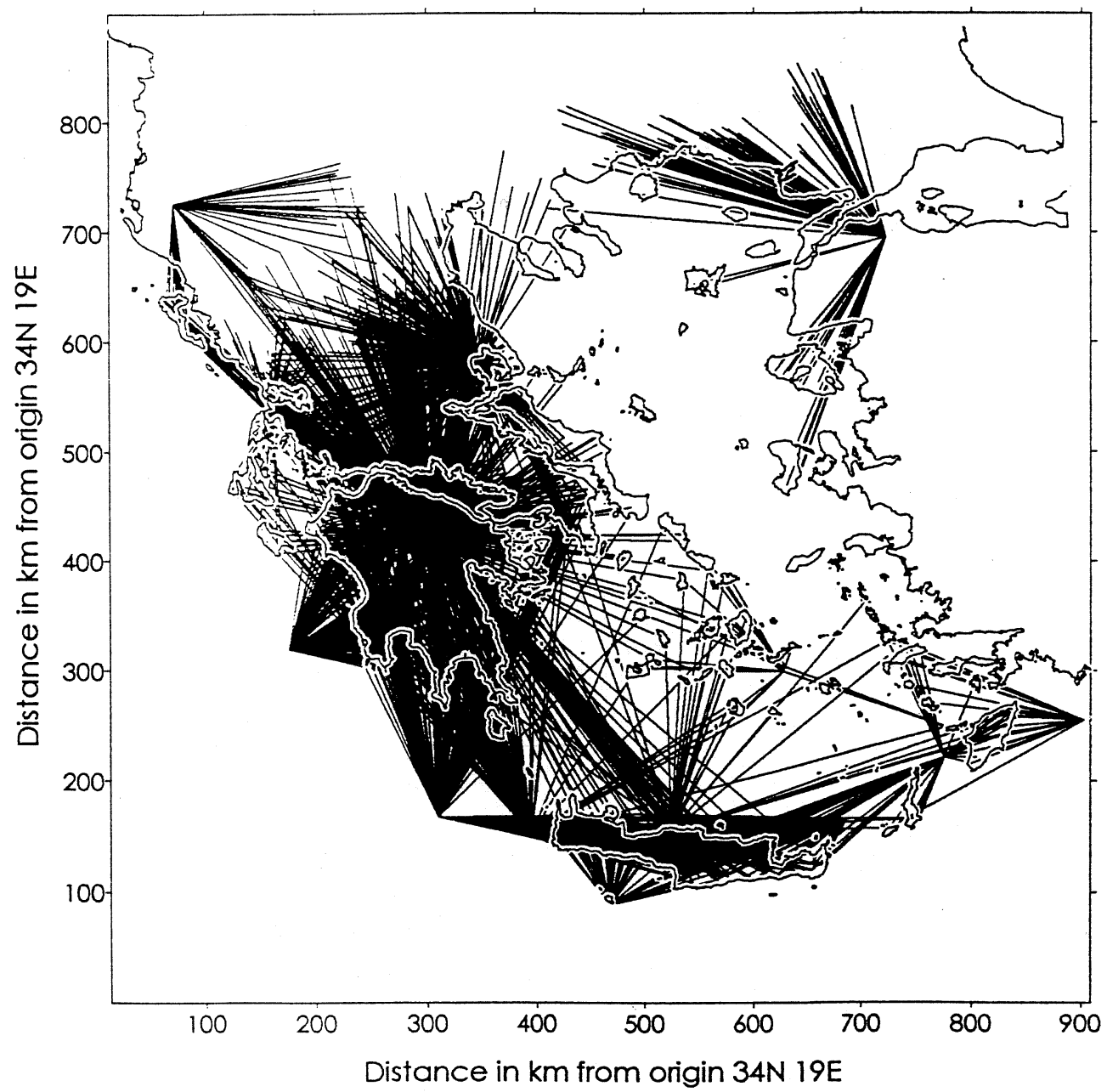

Fig. 4b. The ray path coverage of the region is shown for the lower layer.

very good for both layers. This is because the macroseismic intensity is easily measured at many points on land; therefore there is a large amount of observational data for a single event.

In order to resolve the lateral variation of the attenuation structure after inverting the intensities, the initial (1st) block configuration shown in fig. 3, was shifted by half a block size in northwest direction; we obtained another set of solutions for the 2nd block configuration.

\section{Discussion and conclusions}

The results of the inversion for the attenuation structure are shown in figs. 5 and 6 . Negative values correspond to high $Q$, thus to low attenuation, and positive values correspond to low $Q$, thus to high attenuation. The standard errors obtained were less than $1.0 \times 10^{-2} \mathrm{~s}^{-1}$ for all the blocks.

The stability and the reliability of the solution depend on the values of the diagonal elements of the resolution matrix. Figure $7 a, b$ 


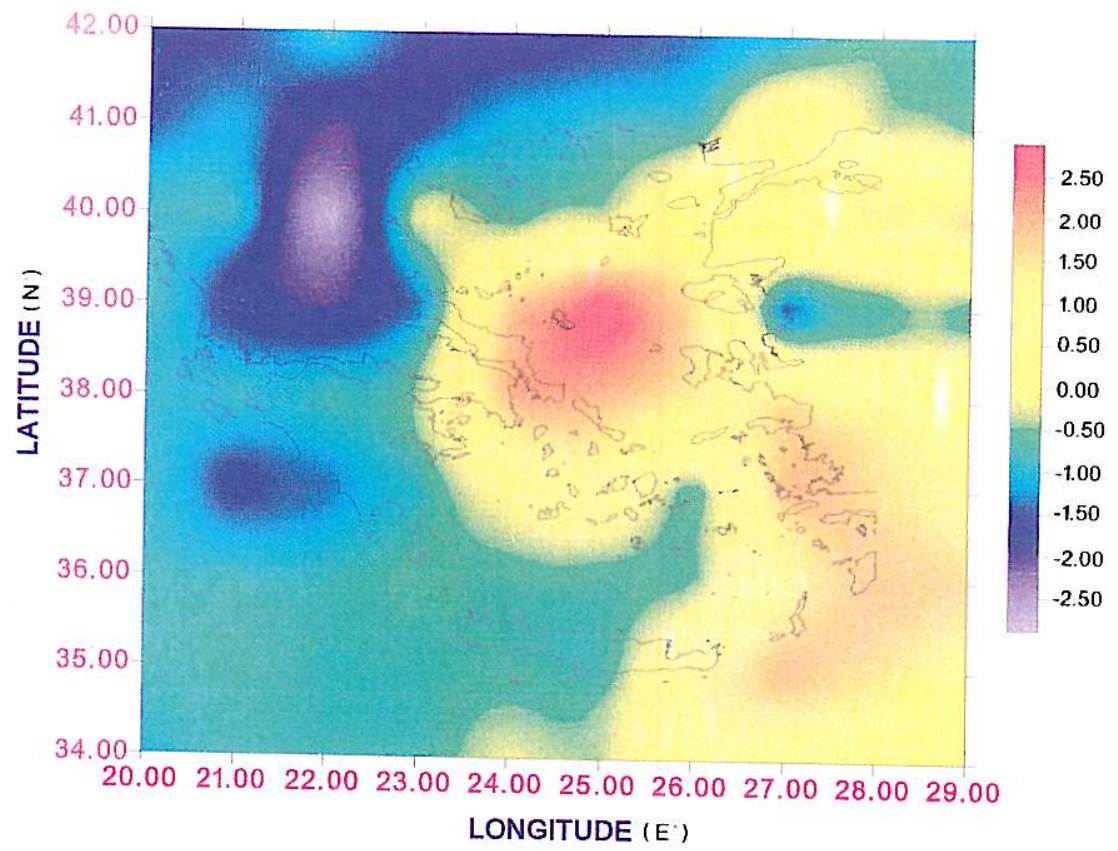

Fig. 5. The results of the inversion are shown for the attenuation structure in the first layer $(0-20 \mathrm{~km})$. Negative values correspond to high $Q$ (low attenuation) and positive values correspond to low $Q$ (high attenuation).

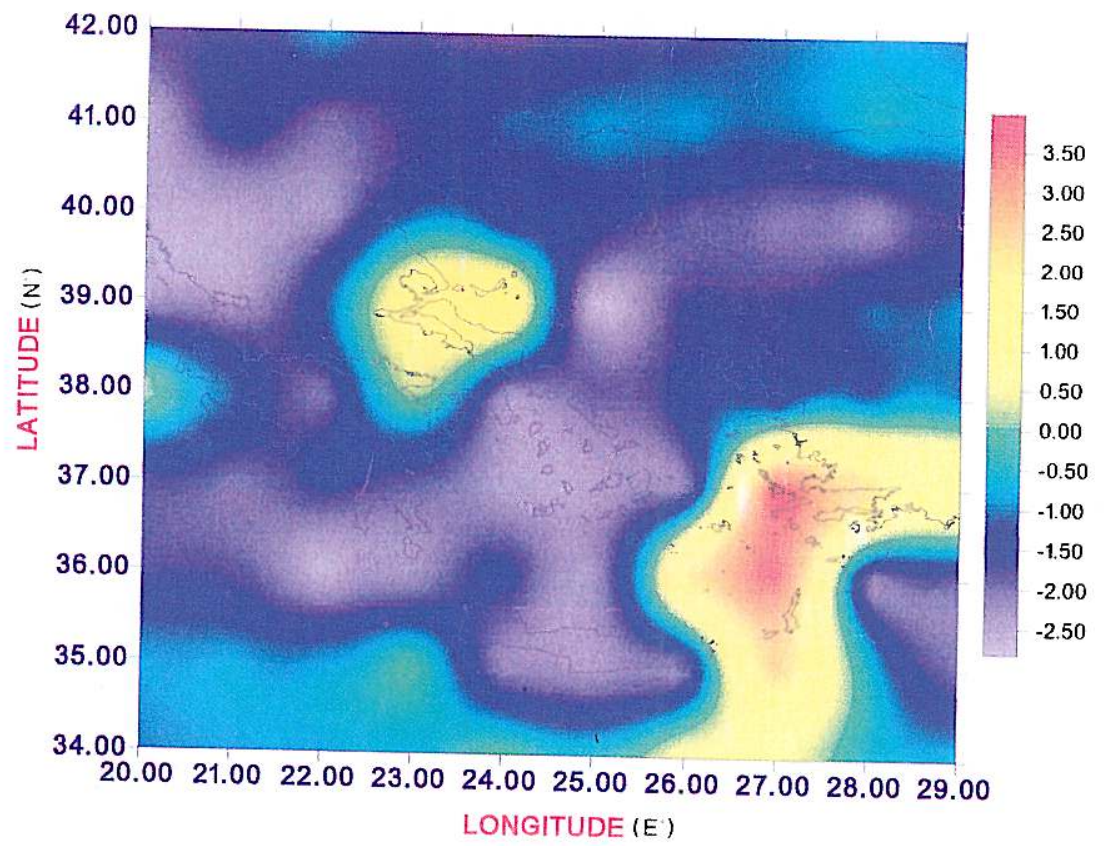

Fig. 6. The results of the inversion are shown for the attenuation structure in the second layer $(20-40 \mathrm{~km})$. 

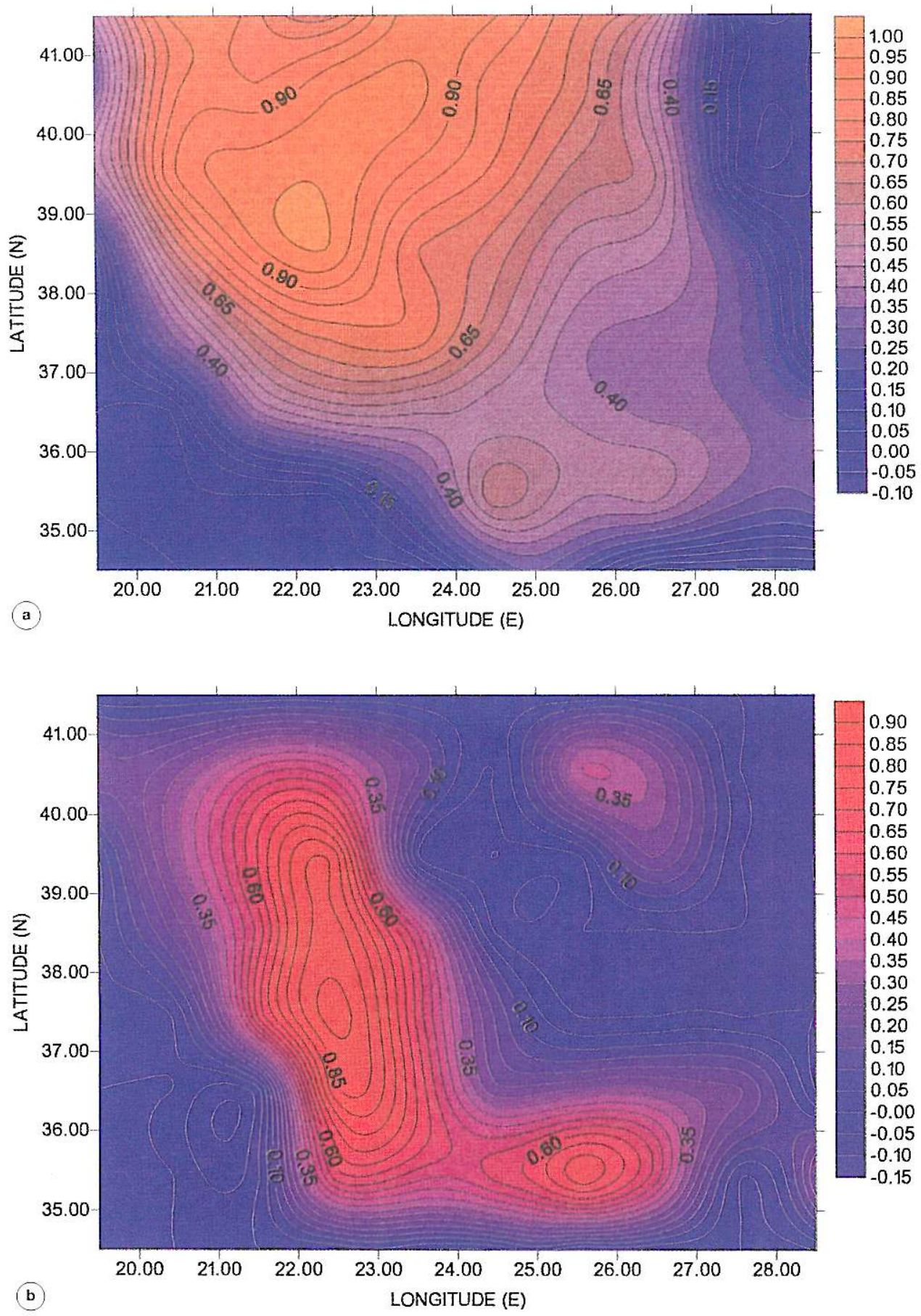

Fig. 7a,b. The resolution matrix is shown for the upper (a) and lower (b) layers, respectively. 
shows the resolution matrix. According to numerical experiments (Hashida and Shimazaki, 1984) solutions with a resolution higher than 0.35 are considered reliable. So, it can be shown that the resolution is rather high. Only in the peripheral blocks is the resolution poor as was expected, due to the lack of crossing rays penetrating these blocks. Therefore, the solutions in the peripheral areas should be discussed with great care.

Visible contrasts appear in the attenuation structure. In the upper layer (fig. 5), low $Q$ is dominant in the Aegean sea, while high $Q$ is dominant in continental Greece and adjacent areas. The lowest $Q$ region was found in the Central Aegean sea. The highest $Q$ region corresponds to Central continental Greece. As regards the second layer $(20-40 \mathrm{~km})$, low- $Q$ zones were obtained in the southeastern part of the Hellenic arc, and in Central Greece as well (fig. 6). The same picture of the attenuation structure was also found by Hashida et al. (1988) using different earthquake data.

It should be noted that the low- $Q$ regions in the first and second layers almost correspond to the distribution of Neogene-Quaternary grabens. The critical point of the attenuation structure obtained is the upper layer, because the macroseismic intensity differs from point to point even in a small area when the ground conditions change locally. On the other hand, we assumed a uniform amplifying effect of the ground by only taking into account the effect of the free surface. This problem is overcome by taking relatively large blocks in order to include several observation points. Therefore, the results for these blocks will be relatively free from local site conditions because of averaging the effects of local conditions at several stations in the same block.

The correspondence of the low- $Q$ regions with the Neogene-Quaternary grabens suggests that these graben areas consist of fractured materials with relatively high temperature. Heat flow data support this suggestion (Jongsma, 1974). Low- $Q$ regions in the first layer include also the volcanic arc (see figs. 1 and 5). However, in the second layer, low- $Q$ regions were not obtained. Similar features were also found in the Japanese island arc (Hashida, 1989).
Another interesting feature in the attenuation structure is a low- $Q$ area $(20-40 \mathrm{~km})$, found from Eastern Crete to Rhodes and Kos islands. Such a low- $Q$ area is not expected to be due to subducting processes taking place there (McKenzie, 1972; Le Pichon and Angelier, 1979). Thus, it might be an artefact, since few ray paths penetrate the block there.

The comparison of our results with those obtained by other researchers (Ligdas et al., 1990; Drakatos and Drakopoulos, 1991; Hashida et al., 1988) shows that the obtained $Q$ structure correlates well with the velocity and $Q$ pattern of the region.

\section{REFERENCES}

AKI, K. and W.H.K. LEE (1976): Determination of threedimensional velocity anomalies under a seismic array using first $P$ arrival times from local earthquakes, 1 . A homogeneous initial model, J. Geophys. Res., 81, 4381-4399.

ANDERSON, D.L. and R.S. HART (1978): $Q$ of the Earth, J. Geophys. Res., 83, 5869-5882.

Delibasis, N.D. (1982): Seismic wave attenuation in the upper mantle beneath the Aegean, Pure Appl. Geophys., 120, 820-839.

DewEY, J.F. and A.M.C. SENGor (1979): Aegean and surrounding region: complex multiplate and continuum tectonics in a covergent zone, Bull. Geol. Soc. Am., 90, 84-92.

Drakatos, G. and J.C. Drakopoulos (1991): 3D velocity structure beneath the crust and upper mantle of Aegean sea region, Pageoph, 135 (3), 401-420.

DRAKOPOULOS, J.C. (1978): Attenuation of intensities with distance for shallow earthquakes in the area of Greece, Boll. Geofis. Teor. Appl., 20, 114-130.

Fytikas, M., O. GiUliani, F. InNOCENTI and R. MAZZUOLI (1976): Geochronological data on recent mag matism of the Aegean sea, Tectonophysics, 31, 29-34.

GREgersen, S. (1977): P-wave travel time residuals caused by a dipping plate in the Aegean arc in Greece, Tectonophysics, 37, 83-93.

GutengerG, B. and C.F. Richter (1942): Earthquake magnitude, intensity, energy, and acceleration, Bull. Seism. Soc. Am., 32, 163-191.

GutenBERG, B. and C.F. Richter (1956): Earthquake magnitude, intensity, energy, and acceleration (second paper), Bull. Seism. Soc. Am., 32, 19-89.

HASHIDA, T. (1989): 3D seismic attenuation structure beneath the Japanese islands and its tectonic and thermal implications, Tectonophysics, 159, 163-180.

HASHIDA, T. and K. SHIMAZAKI (1984): Determination of seismic attenuation structure and source strength by inversion of seismic intensity data: method and numerical experiment, J. Phys. Earth, 29, 299-316.

HASHIDA, T., G. STAVRAKAKIS and K. ShimaZAKI (1988): Three-dimensional seismic attenuation structure be- 
neath the Aegean region and its tectonic implication, Tectonophysics, 145, 43-54.

JACOBY, W.R., N.K. AgARWAL and H. BERCKHEMER (1978): Crustal and upper mantle structure of the Aegean arc from travel time residuals and gravity, in Alps, Apennines, Hellenides, edited by H. Closs et al., I.C.G. Sci. Rep., 38, Schweizerbart, Stuttgart, 401-406.

Jongsma, D. (1974): Heat flow in the Aegean sea, Geophys. J. R. Astron. Soc., 37, 337-346.

Le Pichon, X. and J., Angelier (1979): The Hellenic arc and trench system: a key to the neotectonic evolution of the Eastern Mediterranean area, Tectonophysics, $\mathbf{6 0}$, 1-42.

Ligdas, C.N., I.G. MAIN and R.D. AdAmS (1990): 3D structure of the lithosphere in the Aegean sea region, Geophys. J. Int., 102, 219-229.

MAKRIS, J. (1976): A dynamic model of the Hellenic arc deduced from geophysical data, Tectonophysics, 36, 339-346.

MAKrIs, J. (1978): The crust and upper mantle of the Aegean region from deep seismic soundings, Tectonophysics, 46, 269-284.
McKenzIE, D.P. (1970): Plate tectonics of the Mediterranean region, Nature, 226, 239-243.

McKenzie, D.P. (1972): Active tectonics of the Mediterranean region, Geophys. J. R. Astr. Soc., 30, 109-185.

McKenZIE, D.P. (1978): Active tectonics of the AlpineHimalayan belt: the Aegean sea and surrounding regions, Geophys. J. R. Astron. Soc., 55, 217-254.

Ninkovitch, D. and J.D. HAYs (1972): Mediterranean island arcs and origin of high potash volcanoes, Earth Planet Sci. Lett., 16, 331-345.

PAPAZACHOS, B.C. (1973): Distribution of seismic foci in the Mediterranean and surrounding area and its tectonic implication, Geophys. J. R. Astron. Soc., 33, 421-430.

PApazachos, B.C. and P.E. ComnInAKIS (1971): Geophysical and tectonic features of the Aegean arc, J. Geophys. Res., 76, 8517-8533.

Papazachos, B.C. and P.E. Comninakis (1978): Deep structure and tectonics of the Eastern Mediterranean, Tectonophysics, 46, 285-296.

SPAKMAN, W. (1985): Tomographic image of the upper mantle in the Eurasian-African-Arabian collision zone, $\operatorname{EOS}, 66$ (46), 975. 